\title{
El libro de los actos, provisiones y reuniones de la acequia de Favara (1362-1521): aproximación a un registro clave para la historia del regadío en la Huerta medieval de Valencia
}

\author{
Luis Pablo Martínez Sanmartín ${ }^{1}$ y Vicent Terol i Reig ${ }^{2}$ \\ Direcció General de Cultura, Generalitat Valenciana ${ }^{2}$ Arxiu Municipal d'Ontinyent, \\ martinez_luipab@gva.es, ontiarxiu@cv.gva.es
}

\begin{abstract}
Resumen. Frente al peso de la oralidad en el pasado reciente de las comunidades autónomas de regantes de la Huerta de Valencia, la evidencia archivística pone de manifiesto que la escritura tenía un valor estratégico para los regantes durante la Baja Edad Media y la Edad Moderna. La existencia de abundante documentación escrita producida por instancias internas y externas a las comunidades permite conocer su estructura, funcionamiento y evolución a lo largo de los siglos que siguieron a la conquista de Valencia por Jaime I. La comunicación constituye una presentación preliminar de la estructura y los contenidos de un singular manuscrito, el "Libro de los actos, provisiones y reuniones de la acequia de Favara". El volumen recoge buena parte de lo registrado entre 1490 y 1521 por el escribano de la comunidad de regantes de la acequia de Favara, el notario Lluís Masquefa, junto con la transcripción de la descripción de los partidores de la acequia escriturada en 1362, su enmienda parcial en 1372, y los "capítulos" u "ordenanzas" aprobados por la comunidad hasta 1519. La descripción del manuscrito viene acompañada de la valoración de algunos de los aspectos de mayor interés, desde el punto de vista del análisis institucional de las comunidades de regantes medievales valencianas iniciado por Thomas F. Glick.
\end{abstract}

Palabras clave: sistemas de regadío, comunidades de regantes, acequia de Favara, Huerta de Valencia, documentación escrita, ordenanzas.

\begin{abstract}
In comparison to the weight of orality in the recent past of the autonomous communities of irrigators in the Huerta of Valencia, the archival evidence shows that writing had a strategic value for irrigators during the late Middle Ages and the Modern Age. The existence of abundant written records produced by entities internal and external to the communities provides information about their structure, functioning and evolution over the centuries that followed the conquest of Valencia by Jaime I. The present communication constitutes a preliminary approach to the structure and contents of a remarkable manuscript, the "Book of acts, provisions and meetings of the Favara canal". The volume keeps much of what was recorded between 1490 and 1521 by the clerk of the Favara canal, the notary Lluís Masquefa, together with the transcription of the description of the canal's water dividers registered in 1362 , its partial amendment in 1372, and the "chapters" or "ordinances" adopted by the community until 1519. The description of the manuscript is accompanied by an assessment of some of the aspects of greater interest, from the point of view of the institutional analysis of the Valencian communities of irrigators of the Middle Ages pioneered by Thomas F. Glick.
\end{abstract}

Keywords: irrigation systems, communities of irrigators, Favara canal, Huerta of Valencia, written records, regulations.

\section{Introducción}

El volumen 18.602 del Archivo de Protocolos del Real Colegio-Seminario de Corpus Christi de Valencia lleva por título, manuscrito sobre la cubierta de pergamino, Libre dels actes, provesions e ajusts de la séquia de Ffavara (Libro de los actos, provisiones y reuniones de la acequia de Favara). Se trata de una fuente documental excepcional para el estudio de una de las comunidades de regantes históricas de la Huerta de Valencia bajo jurisdicción del Tribunal de las Aguas: la acequia de Favara, que riega la Vega al sur del río Turia, el 
Guadalaviar de época medieval, desde época andalusí (Bazzana y Guichard, 1981; Glick, 2003 [1970]; Guinot, 2007b; Guinot, 2012; Sanchis, 2001).

El notario Lluís Masquefa trabajó como escribano de Favara entre 1490 y 1521. Por lo general, los notarios valencianos que actuaban como escribanos de las comunidades de regantes intercalaban las actas a ellas relativas entre la diversidad de actos registrados en sus volúmenes, copiados en orden cronológico, y en ocasiones acompañados de una tabla de contenidos para facilitar la localización de la información. Masquefa, por su parte, dedicó un volumen para recopilar en él de manera exclusiva la documentación relacionada con la acequia a la que prestaba sus servicios. La documentación recogida informa sobre aspectos muy variados de la dinámica de la comunidad de regantes durante su ejercicio de la escribanía de la acequia, tales como reuniones, visitas de inspección o sentencias de pleitos por el uso del agua.

Los cuadernos que registran los actos producidos mientras Masquefa fue escribano de Favara vienen precedidos por otro cuaderno donde el notario tuvo la precaución de copiar los documentos que garantizaban el statu quo de la acequia, desde el punto de vista físico e institucional. Estos eran el acta de la inspección llevada a cabo en 1362 con la finalidad registrar la nivelación y el ancho de la totalidad de las particiones mayores del sistema de Favara, seguida de su corrección parcial en 1372; y las ordenanzas del canal de riego en vigor en 1446, acompañadas de los nuevos capítulos aprobados por la comunidad hasta 1519, en tiempos de Masquefa.

En las siguientes páginas efectuaremos una descripción de los contenidos del manuscrito, que servirá para efectuar una aproximación preliminar no sistemática a la planta institucional y la dinámica de la comunidad de regantes durante el período cubierto por la documentación.

\section{El manuscrito: estructura y contenidos}

El notario Masquefa era consciente de la singularidad del volumen, de manera que se sintió obligado a indicar expresamente que el contenido transcrito en el mismo poseía fe incuestionable, como si se tratase de uno de sus protocolos, según se puede leer en la nota que encabeza el registro (f. $2 \mathrm{v}$ ):

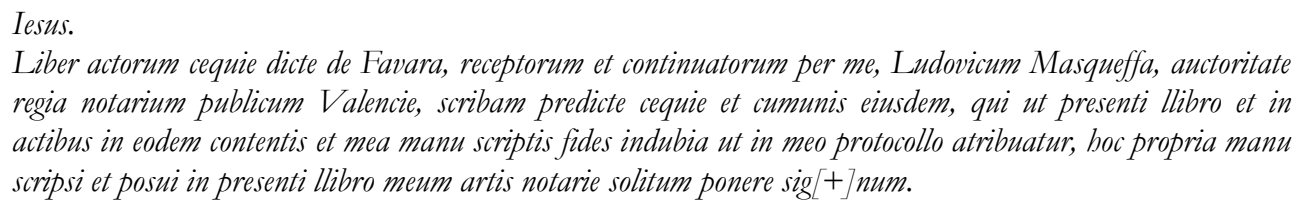

La información contenida en el manuscrito compilado por Lluís Masquefa puede dividirse en tres grandes bloques. El primero (ff. 3r-10v) viene integrado por los traslados o copias auténticas notariales de las inspecciones efectuadas por la comunidad de regantes en 1362 y 1372 y los actos relacionados con las mismas (manifestaciones de conformidad con la visura practicada en 1372, formuladas por diversos actores; referencias a la elaboración de copias auténticas en 1403 y 1598). El segundo comprende la transcripción de las ordenanzas en vigor durante el ejercicio de la escribanía de la acequia por Lluís Masquefa (ff. 11r-30v). Las inspecciones y las ordenanzas fueron deliberadamente copiadas en un mismo cuaderno donde intervinieron un mínimo de tres diferentes escribanos. Ambos bloques vienen precedidos por sendos epígrafes introductorios, destacados entre 
calderones. El tercer conjunto de documentación (ff. 31r-111r), el más extenso y de contenido más diverso, comprende actas de reuniones de los órganos y comisiones de la comunidad de regantes, junto con actuaciones de muy diverso tipo llevadas a cabo por comuneros y oficiales de la acequia entre 1490 y 1521.

\subsection{El "inventario" de la acequia de Favara}

El primer conjunto netamente diferenciado de documentos lleva por título "Lo inventari de la céquia de Ffavara" (f. 7r). Aunque en realidad transcribe el contenido de dos actos protocolizados en 1362 y 1372 por el notario Bernat Ferrer, el epígrafe habla de "inventario" y no de "inventarios" porque probablemente alude a la copia elaborada en 1403 en un único pergamino por el notario Arnau Despuig. Además, mientras que la visura efectuada en 1362 comprendía todo el trazado de la acequia madre, la inspección de 1372 se circunscribió a un corto trecho de su curso, por lo que se trató de una corrección muy limitada de la primera y podía hablarse de un único "inventario".

El acta recibida por Bernat Ferrer el 1 de diciembre de $1362^{1}$ consigna la medición y nivelación de los partidores de la acequia que fue llevada a cabo por Andreu Julià, maestro mayor de las obras de la catedral de Valencia, en compañía del sequier (acequiero) Guillem Abelló, ciudadano de Valencia, su acompanyat (literalmente, "acompañado") Bernat Despujol y los labradores Joan Bonfill, Bernat de Montblanc, Bernat Guich, Jaume Eiximeno y Jaume Fortea, veedors (veedores), oficiales de la acequia de Favara que actuaron por mandato expreso de los hereters (regantes terratenientes) de la acequia, reunidos en plener consell e parlament (en consejo y parlamento pleno).

Desconocemos las funciones del acompanyat, figura documentada en la comunidad de regantes todavía a comienzos del siglo $\mathrm{XV}^{2}$ que no es citada durante la ejercicio de la escribanía por Lluís Masquefa; pero tanto el sequier (oficial encargado de la buena conservación y funcionamiento del sistema de regadío con jurisdicción sobre las disputas entre los usuarios), como los veedors (cuyas funciones primordiales eran la supervisión del riego en su distrito y el asesoramiento y control de la ejecutoria del acequiero), ${ }^{3}$ desempeñan un papel protagonista en la comunidad en el tránsito del siglo XV al XVI. Tampoco conocemos si entre el "consejo y parlamento pleno" de la acequia en el siglo XIV y el Comú (Común) del siglo XV (la asamblea de hereters depositaria de la máxima autoridad de la comunidad) existe relación de identidad. La existencia de una filiación entre ambas es plausible, aunque para ello deberíamos poder comparar la planta institucional de ambos órganos. Sabemos, por ejemplo, que el Comú era la asamblea de los regantes terratenientes (hereters) de la que estaban excluidas las mujeres y los hombres no

1 Publicada a partir de una copia registrada por la Cort de la Governació por Thomas F. Glick (2003 [1970], pp. 467-469).

2 Así, el 1 de septiembre de 1419 el lloctinent de sequier de la acequia de Favara, Jaume Uguet, los veedors Francesc Carnicer y Vicent Desplà, y Llorenç Botinyà y Bartomeu Teulada, "acompanyats de aquells", pronunciaron sentencia en el pleito que enfrentaba a Berenguer Lleopart, de una parte, y Domingo Martí y Jaume Miró, de la otra, por el uso de una acequia de desagüe medianera entre sus propiedades (un “escorredor miger"): Archivo del Real Colegio-Seminario de Corpus Christi de Valencia (ACCV), Protocolos, 6.422 (Domingo Barreda, 1419).

3 En época de Masquefa la acequia de Favara contaba con once veedores, adscritos individualmente a diferentes secciones de riego articuladas por brazos principales derivados de la acequia madre: Patraix, Raujosa, Sant Vicent, Monroig, Lo Tell (l’Altell), La Gàbia, Alfafar, Benetússer, Massanassa, Catarroja y Albal. 
terratenientes (arrendatarios, jornaleros y, por descontado, esclavos), pero desconocemos (aunque es plausible) si el consell o parlament se constituía de igual modo.

La medición de diciembre de 1362 se llevó a cabo meses antes del asedio de la ciudad de Valencia por el rey de Castilla Pedro I. Los regantes de Favara temían la conflictividad que podría generar la destrucción por el ejército enemigo de los partidores del canal de riego, verdadera materialización física de los derechos de acceso al agua. El acto registrado diez años después por Bernat Ferrer, el 19 de abril de 1372, recoge una nueva medición y nivelación limitada a dos partidores ubicados aguas arriba del molino de $\mathrm{Na}$ Barcelona, llevada a cabo por iniciativa propia del sequier Pere Eiximeno y cinco veedores de la acequia de Favara, los labradores Bernat Guich, Bernat de Montblanc, Pere Desplà, Bartomeu Martí i Guillem Desplà, que habían detectado en este tramo de la acequia madre errores y omisiones en la nivelación efectuada diez años antes.

El epígrafe introductorio del traslado de ambas actas notariales viene acompañado de sendas notas al margen (f. 7r) que ponen de manifiesto el rol activo de Lluís Masquefa en la elaboración de la nueva copia del "inventario". En la primera leemos: "Don Perellós tiene el original en forma" ("Don Perellós té l'original en forma”). La segunda reza: "Ahora yo lo tengo en la caja de las cartas" ("Ara yo'l tinch en la caxa de les cartes"). La comunidad de regantes no debía custodiar los instrumentos originales redactados por Bernat Ferrer, de modo que, en algún momento tras su acceso al ejercicio de la escribanía de la acequia, Masquefa se vio compelido a solicitar a una de las personalidades socialmente más relevantes de la comunidad, Gener Rabassa de Perellós i Montagut, señor de Benetússer (†1513), calificado de "noble"5 (epíteto reservado a los miembros de la alta aristocracia regnícola), el acceso a la copia auténtica de las preciosas inspecciones que este poseía. Una nota al pie del "inventario", dañada por la acción de los insectos xilófagos, indica que Masquefa ordenó hacer la copia en algún momento del año 1510 ("[Lo pre]sent trellat fiu fer yo, [Lluis Mas]queffa, scriv[à] [...] any MDX").

Gener Rabassa de Perellós tenía un interés muy particular en la custodia del documento que garantizaba la partición equitativa del agua entre los usuarios del sistema de riego, según se practicaba en el tercer cuarto del siglo XIV. Como señor de Benetússer, sus tierras y fuentes de renta feudal estaban enclavadas en la segunda sección del territorio regado por la acequia de Favara, conocida como "Els Llocs" (los Lugares). Este espacio, integrado por los pueblos de Benetússer, Alfafar, Sedaví, Catarroja, Massanassa y Albal, era regado por "braços atandats" ("brazos atandados"), canales secundarios sometidos a régimen de tandeo permanente entre sí, que recibían en conjunto una proporción de agua menor a la que disfrutaban los "braços corribles" de la primera sección del canal. Estos últimos tenían sus tomas permanentemente abiertas, en condiciones normales de disponibilidad de agua en el río (Mateu, Marco, y Sanchis, 1999a y 1999b; Sanchis, 2001, pp. 76, 78-80; Sanchis y Ruiz, 2003, 22-23).

La documentación coetánea denomina al distrito de cabecera con acceso privilegiado al agua del sistema de Favara "L'Horta de València" (la Huerta de Valencia) o simplemente "L'Horta", por comprender lugares y partidas rurales enclavadas dentro de los límites de la jurisdicción particular de la ciudad de València (aunque a efectos analíticos resultaría más adecuada la denominación "Huerta de Favara"). Además de su menor acceso al agua gestionada por la comunidad de regantes, Els Llocs se encontraban en situación

4 En el original, al sustantivo "cartes" sigue un adjetivo de difícil lectura.

5 Sobre el linaje Rabassa de Perellós como fruto del entronque de un acaudalado linaje regnícola de juristas, los Rabassa, con el los Perellós, perteneciente a la nobleza catalana, véase R. Narbona (1989). 
estructuralmente débil frente a L'Horta, por su posición en la cola del sistema de riego: los labradores de Els Llocs estaban a merced de la buena praxis tanto de los regantes de cabecera como de los oficiales de la comunidad encargados de velar por el bien común. Resulta lógico, pues, que los señores de los lugares enclavados en la cola del sistema de Favara hiciesen acopio de instrumentos probatorios de sus derechos.

Más difícil de entender resulta, a priori, que el señor de Benetússer librase al notario escribano de la acequia de Favara el preciado "inventario", garante de sus derechos y de los de sus vasallos. Un hecho objetivo permite apuntar una explicación. Lluís Masquefa trasladó su domicilio a Benetússer en torno al 31 de enero de 1490, cuando el notario Francesc Trilles registró la compra por Masquefa al labrador Jaume Resclosa de nueve hanegadas de tierra campa en término de la localidad, que proféticamente limitaban con la propia acequia de Favara y estaban sometidas a dominio directo de Gener Rabassa de Perellós. ${ }^{6}$ Muy probablemente, pues, Masquefa era vecino de Benetússer y censatario del señor del lugar cuando accedió al cargo de escribano de Favara, el 12 de abril de ese mismo año, por muerte del notario titular, Miquel de Puigmitjà. Fue precisamente Francesc Trilles (que actuaba en Benetússer al servicio de la señoría), quien, según indica Masquefa (f. 31r), registró su elección como nuevo escribano de la comunidad de regantes:

Die XII aprilis anno $M^{\circ}$ CCCC LXXXX ab carta reebuda per lo discret en Francesch Trilles, notari per lo Comú de la céquia de Favara per mort del discret en Miquel de Puigmigà, notari, fuy fet yo Luís Masqueffa notari, escrivà de la dita céquia, e per ço en lo present llibre continue tots los actes de aquella.

Más allá de su vínculo enfitéutico y vasallático, la relación clientelar que Masquefa mantenía con el señor de Benetússer debió facilitarle el acceso al oficio de escribano de Favara, y también explicaría que Gener Rabassa de Perellós accediese a cederle el preciado "inventario", ya fuese a título permanente o por tiempo limitado a la ejecución de la nueva copia. El acceso a la escribanía de Favara también puede entenderse en el marco del interés del señor de Benetússer por controlar los resortes institucionales de la comunidad.

\subsection{Los capítulos u ordenanzas de la acequia de Favara}

El inventario de la acequia viene seguido en el primer cuaderno del volumen por el traslado de las ordenanzas de la comunidad de regantes, precedidas por el siguiente epígrafe: "Iesus. Capítols de la céquia de Ffavara" (f. 11r). Nada más encontramos en el anverso del folio donde se escribió, salvo una preciosa anotación al pie que indica la superficie de la tierra regada por la acequia de Favara en 1515, acompañada de una estimación de la extensión regada en la zona pantanosa que limitaba con Favara en las cotas bajas, la Marjal:

Caffiçades pagadores II ${ }^{\mathrm{m}}$ DCL caffiçades, fet aquest comte a XXII de ffebrer any MDXV en casa del mestre rac[ional]; ab les Margals, que s[ón] $\mathrm{II}^{\mathrm{m}}$ cafiçades, són [ ].

Según el recuento, efectuado en casa de otra de las personalidades socialmente dominantes en la comunidad de regantes, Joan Escrivà de Romaní, mestre racional (auditor de cuentas) del Reino de Valencia y señor de Patraix, la acequia de Favara regaba a comienzos del siglo XVI un total de 2.650 cahizadas (1.321'29 hectáreas), tierras que debían pagar el canon dinerario de mantenimiento del sistema, la tasa conocida como sequiatge (cequiaje); ${ }^{7}$

6 ACCV, 21.753 (Francesc Trilles, 1490-1497), sin foliar.

7 A comienzos del siglo XIX, Favara regaba algo más de 3.114 cahizadas, de acuerdo con los datos publicados por F. J. Jaubert de Passa (1991 [1844], vol. I, p. 412; vol. II, p. 229). 
mientras que la Marjal regaba unas 2.000 cahizadas (997'2 hectáreas). La comunidad de la Marjal disponía de su propia estructura de gestión y de gobierno, dependiente de la ciudad de Valencia (Glick, 2003 [1970], 93-101; Lluch y Beltrán, 1991), pero mantenía, como se desprende de la documentación, una particular vinculación con Favara.

Las ordenanzas compiladas por Masquefa están integradas por un total de 74 capítulos, que incluyen los 67 que estaban en vigor en 1446, más otros siete que fueron aprobados en diferentes reuniones (ajusts) del Comú de la acequia celebradas los años 1452, 1456, 1492, 1493, 1502, 1504 y 1519. Los "capítulos u ordenanzas", como a ellos se refiere la documentación, vienen precedidos de un índice de contenidos, titulado "Taula dels capítols de la céquia de Favara" (f. 11v), que relaciona las rúbricas de cada ordenanza, numeradas individualmente y acompañadas de referencia al folio en que se encuentran copiadas. Tanto la cuidada caligrafía y mise en page como el hecho de que la parte del cuaderno donde se copiaron los capítulos fuese foliada son prueba de la relevancia que la materia tenía, a ojos del escribano de la comunidad.

Ambos conjuntos de capítulos se distinguen netamente. Los posteriores a 1446 son de redacción prolija, que aporta información acerca del ajust en que fueron adoptados y las razones de su adopción. No todos, además, poseen rúbrica que los singularice. Por el contrario, los del primer bloque van precedidos por su propio título, son de redacción sintética, desprovista de cualquier referencia al contexto histórico en que fueron aprobados, y su relación viene precedida de un epígrafe común que da razón de su origen de modo sucinto:

Iesus Marie filius.

Capítols fets per lo Comú de la céquia de Favara, ab los quals lo cequier qui en les festes de Pasqua de Resurecció de l'any de la Nativitat de Nostre Senyor Déu Mi CCCC XXXXVI trau la céquia de Ffavara s'a ha regar ${ }^{8}$ lo temps per lo qual traurà la dita céquia.

Masquefa, o quien por él puso orden en los capítulos, se equivocó en su enumeración a partir del número 68, al asignar el LXVIII a un párrafo introductorio de la ordenanza relativa al pago del notario escribano por sus trabajos; de manera que el texto real del capítulo recibió el número LXVIIII. El error se arrastró en la numeración de los siguientes capítulos, y fue transmitido a las ordenanzas que, a requerimiento de la comunidad de regantes, fueron autorizadas por la Gobernación General del Reino de Valencia en 1597. El archivo de la Acequia de Favara custodia una copia auténtica elaborada en 1618 por el notario Agustín Queito, escribano de la acequia, con la que hemos trabajado.

Las ordenanzas de 1597 suman a las compiladas por Masquefa los capítulos aprobados hasta esa fecha, y constituyen el antecedente conocido más próximo de las ordenanzas aprobadas por la Gobernación en 1701, publicadas por François Jacques Jaubert de Passa en su célebre estudio sobre los regadíos del este de la península ibérica (Jaubert de Passa, 1991 [1844], vol. I, pp. 5-101). Por el interés de su estudio comparado, y a fin de disponer de una numeración depurada de los capítulos, se ha confeccionado la tabla que insertamos tras la bibliografía, donde se relacionan los epígrafes de las dos compilaciones de

8 Sic, probablemente por "regir".

9 El manuscrito carece de signatura y presenta paginación (que no foliación) en arábigos. Agradecemos a la comunidad de regantes de la acequia de Favara, en especial a su síndico presidente, el Sr. D. Francisco Vázquez Olmos y su secretario jurídico, el Sr. D. Alfonso Pastor Madalena, la colaboración prestada para la elaboración de este trabajo. 
ordenanzas, en confrontación con la numeración depurada en arábigos que seguimos en la presente investigación.

Desde el punto de vista de la producción del manuscrito, los capítulos 1 a 69 (LXX en la errónea numeración original) corresponden con la normativa de la comunidad de regantes en vigor en el momento del acceso de Masquefa al cargo de escribano, integrada por el bloque de capítulos en vigor en 1446 y sendas ordenanzas aprobadas en 1452 y 1456. Aunque, como sabemos, presentan diferencias formales (redacción sintética los primeros, redacción extensa las segundas), todos ellos van precedidos de su correspondiente rúbrica entre calderones, y fueron copiados por una misma mano. Por el contrario, los cinco capítulos estatuidos en 1492, 1493, 1502, 1504 y 1519, que comparten con los de 1452 y 1456 una redacción in extenso, carecen de título introductorio y fueron copiados por diferentes manos, de manera un tanto descuidada (textos escritos a posteriori que se acomodan en huecos de manera forzada; textos cancelados de modo grosero; un folio en blanco; foliación ad hoc). Masquefa entendió que debía seguir actualizando la lista de las ordenanzas mientras estuviese en ejercicio de la escribanía, si bien ello arruinó la compostura de este importante bloque de contenido del volumen.

El trabajo efectuado por Masquefa permite reconocer las ordenanzas medievales y de la temprana Edad Moderna como un constructo histórico extremadamente fiel a su historicidad. En efecto, frente al esfuerzo de sistematización racionalizadora que caracteriza el texto de las ordenanzas de 1701, las ordenanzas anteriores son el resultado de la adición paulatina de nuevos capítulos acordados por la comunidad, que regulaban aspectos no tratados por las anteriores, o limitaban, precisaban o matizaban el alcance de las primeras.

La ordenación cronológica de los capítulos, de acuerdo con la fecha de adopción, es producto del carácter instrumental de las ordenanzas en el contexto del sistema de funcionamiento de la comunidad de regantes en la época. En efecto, frente al modelo de gestión directa por la comunidad característico de la historia reciente de las comunidades de regantes de la Huerta, entre la conquista de Valencia por Jaime I y el siglo XVII imperó un sistema que externalizaba en buena medida la carga de la gestión del sistema de riego en la figura del sequier, responsable máximo de su buena conservación y funcionamiento (Glick, 2003 [1970], pp. 75-86; Guinot, 2007a). Con carácter bienal, Favara convocaba mediante pregón un ajust del Comú, con la finalidad de otorgar la colecta del cequiaje mediante subasta conducida por un profesional de la correduría convocado al efecto. Ganar la subasta del sequiatge conllevaba la asunción por el ganador de las responsabilidades del cargo de acequiero. Según las ordenanzas anteriores a 1701, en la subasta podía pujar cualquier hereter de la acequia (los "extraños" ajenos a la comunidad no podían hacerlo, capítulo 19), con exclusión de los propietarios o arrendatarios de molinos (capítulo 17), de los hereters de Favara que eran a su vez hereters de la vecina acequia de Rovella (capítulo 18), y de quienes hubiesen pleiteado con la comunidad (capítulo 20).

Ganaba la subasta quien se comprometía a la colecta de un cequiaje de menor importe, y se encontraba en condiciones de constituir fianzas y avales por valor de 1.000 florines. La postulación al ejercicio del oficio de acequiero implicaba, pues, un percepción racional de la expectativa de costes y beneficios por parte del candidato; algo que sólo estaba al alcance de un grupo de hereters que constituían verdaderos profesionales del riego. Estos eran, de ordinario, labradores que eran buenos conocedores del sistema y de su relación con las restantes acequias de la Huerta, con las que había que coordinarse en tiempo de tandeo del río. Además, disponían de buenos contactos dentro y fuera de la comunidad, que les suministraban apoyo político y cobertura económica para el desempeño de su función. De hecho, se ha documentado la existencia en el siglo XV de labradores sequiers altamente 
profesionalizados y relacionados entre sí, que prestaron sus servicios en diferentes comunidades de la Huerta de Valencia (Martínez, en prensa). Conviene reseñar, no obstante, que la documentación de Masquefa pone de manifiesto que el acceso al oficio de acequiero en Favara no estaba restringido a los labradores: es el caso de Guillem Abelló, ciudadano de Valencia, sequier en 1362; los pelaires o fabricantes de paños de lana Jordi Soriano y Antoni Faios, sequiers, respectivamente, en los bienios 1506-1508 y 1514-1516; o mestre Joan de Paredes, obrer de vila, acequiero entre 1519 y 1521.

Para acceder al ejercicio del cargo, el ganador de la subasta debía jurar ante el Comú el respeto de unas cláusulas que no eran otras que las ordenanzas, expresión escrita de las normas consuetudinarias de gobierno de la acequia. Es por ello que los preceptos que las integran recibían en la época el nombre de capitols: no solo eran normas de obligatorio cumplimiento por todos los usuarios del sistema, con independencia de su condición social, sino que constituían verdaderas estipulaciones contractuales reguladoras de las obligaciones del acequiero. De hecho, parece claro que el motor de la compilación por escrito de ordenanzas detalladas es la práctica recurrente de la subasta del sequiatge y el cargo de sequier. Significativamente, el oficio de acequiero es el único de los establecidos por la comunidad de regantes cuyas obligaciones y competencias eran minuciosamente detalladas por las ordenanzas. De hecho, únicamente 5 de los 74 capítulos no aluden ni explícita ni implícitamente al sequier, e incluso podemos considerar que dichos capítulos fueron puestos por escrito para el mejor control y desempeño del oficio de acequiero.

Ello se advierte claramente en la íntima relación que guardan entre sí dos importantes capítulos, el 30 ("De les gràcies dels atandats") y el 31 ("Dels atandats"). Las "gracias" a las que alude el primer precepto son las concesiones voluntarias de agua (aigua de gràcia) efectuadas por los regantes sobirans, de la cabecera del sistema, en favor de los regantes jussans, de la sección de cola. El capítulo 30 especifica la obligación del acequiero de atender las demandas de agua de gracia formuladas por los jussans única y exclusivamente dentro de los días en que les correspondía la tanda de riego. El capítulo 31 no menciona al acequiero, limitándose a especificar cuáles eran los braços atandats. Sin embargo, está claramente concebido como desarrollo o complemento lógico del primero, no sólo para limitar posibles abusos por parte de los regantes que quisieran regar fuera de su tanda, sino para facilitar la compleja tarea del acequiero, en caso de duda o conflicto, y poner coto a posibles cesiones irregulares de agua por el sequier en favor de regantes a quienes no correspondería el turno de riego (ff. 18r-v):

Dels atandats

\begin{abstract}
XXXI Ítem, declaram que los que deuen ésser entre si atandats són los infrasegüents, ço és: lo partidor de Na Stadella, e lo partidor apellat de Na Picabarralla, e lo partidor de Sent Jordi, e quatre caffiçades en la alqueria [que] solia ésser d'en Passadores, e la alqueria dels Regans // [f. 18v] e la cadira de la Carrera Orba són de la tanda del disabte; e Benetúcer és de la tanda del diumenge; e lo partidor de Alffaffar e de Sedaví, e la cadira de Benetúçer són de la tanda de dilluns e del dimats; e Maçanaça, e Cataroga e Albal són de la tanda de di[mecr]es, e del dijous, e del divendres, tro al sol exit lo disapte.
\end{abstract}

La sucesión de capítulos también refleja los cambios históricos de la morfología física de la red de canales. Los sistemas tradicionales de regadío por gravedad de la Valencia medieval presentaban dos dimensiones, una tangible e otra intangible, unidas por estrecho vínculo. Rasgos físicos como el trazado de la red de canales, el aforo de las particiones y los aliviaderos, o el patrón de implantación de los usos (regadío, molinería hidráulica, etc.) constituían una expresión material de la jerarquía de derechos e intereses de los diferentes grupos de usuarios (regantes frente a molineros; regantes sobirans frente a regantes jussans; 
etc.) que eran fruto tanto del diseño inicial del sistema como de la negociación continua tras su entrada en servicio. Los acuerdos (o desacuerdos) podían en cualquier momento producir cambios relevantes en la materialidad de la red de canales; cambios que, a su vez, conducían a la aprobación de nuevos capítulos por la comunidad. Así, las menciones en la documentación de Masquefa a las acequias Nova (Nueva) y Vella (Vieja) son fiel reflejo de la radical reestructuración de tramo inicial de la acequia madre de Favara acaecida entre 1424 y 1434.

La gran riada de 1424 provocó un cambio en el trazado del Guadalaviar que acercó peligrosamente el río a la ribera derecha, en paralelo a la cual discurría el tramo inicial del cajero de la acequia madre de Favara. En ajust celebrado el 30 de enero de 1424, el Comú aprobó la práctica de una inspección de urgencia por un grupo de bereters a los que se otorgaron poderes para estudiar la solución más adecuada, e incluso contratar créditos en nombre de la comunidad para poder financiar las obras. Al día siguiente la delegación de hereters acordó, en el lugar de los hechos, que debía modificarse el recorrido del cajero de la acequia madre, de manera que el río dejase de ser una amenaza para el sistema, y que debía negociarse la contratación de un crédito censal para poder adquirir el predio de un mudéjar de la moreria de Mislata por donde debía desviarse la acequia. ${ }^{10} \mathrm{~A}$ finales de ese mismo año se documentan negociaciones del Comú de Favara con el de la vecina acequia de Mislata. ${ }^{11}$

Según se infiere de la lectura de una sentencia arbitral promulgada el 27 de abril de 1434, registrada por el notario Joan de Campos, ${ }^{12}$ más allá de las imprescindibles excavaciones, se pretendía aprovechar como parte del nuevo trazado Favara el tramo final de uno de los canales secundarios principales derivados de la acequia de Mislata, el braç dels Moros (brazo de los Moros) que, de hecho, desembocaba (engranava) en la acequia madre de Favara. Aguas arriba del punto del braç dels Moros donde se pretendía insertar la acequia madre de Favara, empero, se encontraba ubicado un molino batán y arrocero. Enterado del proyecto, su señor útil, Guillem Castellano, manifestó su oposición por los perjuicios que, a su entender, le causaría el proyecto, puesto que temía que la entrada del agua de Favara en el cajero del brac dels Moros provocaría en éste un incremento del nivel del agua (regolf) que dificultaría el funcionamiento de su ingenio. Con apoyo de la señora de Mislata, Teresa d'Íxer, titular de la señoría directa del molino, denunció el proyecto ante la Corte de la Gobernación. El conflicto, sin embargo, condujo a una negociación en el contexto de un procedimiento arbitral que propició una modificación del proyecto beneficiosa para todas las partes. La sentencia arbitral de 1434, en efecto, determinó que el nuevo cajero de la acequia madre de Favara debía desembocar en el brac dels Moros aguas arriba (y no abajo) del molino de Castellano. Favara culminaba así el proyecto de desvío de su cabecera; Castellano podía incrementar notablemente la potencia de su ingenio (y, por consiguiente, sus beneficios), al sumar al agua del braş dels Moros el caudal íntegro de Favara; mientras que la señoría directa del molino se beneficiaría por el incremento del valor del molino. Los jueces árbitros llevaron a cabo una justa y equitativa asignación de costes entre los interesados, de modo que en la financiación de las obras a ejecutar participaron de manera proporcional a su beneficio las tres partes favorecidas por el acuerdo.

Fue la materialización de este proyecto la que dio lugar a que la comunidad de regantes distinguiese entre las acequias Vella y Nova. No eran dos acequias distintas, sino dos tramos consecutivos de la misma acequia madre de Favara, aguas arriba y aguas abajo del molino

10 ACCV, Protocolos, 6425 (Domingo Barreda, 1424), sin foliar.

11 Véanse los acuerdos adoptados por el Comú de Favara en ajust celebrado el 19 de noviembre de 1424 ACCV, Protocolos, 6425 (Domingo Barreda, 1424), sin foliar.

12 Archivo del Reino de Valencia (ARV), Protocolos, 422 (Joan de Campos, 1432-1434), sin foliar. 
de Castellano, conocido históricamente también por los nombres de molino de Jaume Gil, de Galceran Bou, de Aranda, Gran (Grande) de Mislata o, simplemente, de Mislata, como es citado en las ordenanzas de 1701 (Borrego, Escrivà y Ramírez, 1992; Rosselló, 1989). Las obras llevadas a cabo obligaron a la introducción en los capítulos de nuevas precisiones en cuanto a las obligaciones del sequier respecto al mantenimiento de la acequia madre. El contraste en las ordenanzas medievales de Favara entre la dispersión de las normas de aplicación al molino de Mislata y el elevado grado de formalización de los preceptos relativos al segundo gran molino sobre la acequia madre, conocido como d'en Valls, d'en Gil Pérez, de Sanoguera o de Nou Moles (como es citado en 1701), es un claro efecto de la mayor antigüedad del segundo dentro del sistema de Favara respecto al primero (Fig.1). Ya en 1446, las obligaciones del molinero d'en Gil Pérez (Nou Moles) venían claramente sistematizadas y sintetizadas en 4 capítulos (55 a 58), mientras que las del molinero d'en Jaume Gil (Mislata) debían colegirse de la lectura de 8 capítulos (4, 5, 7, 8, 9, 10, 12, 35), redactados desde la óptica de las obligaciones del sequier.

Las ordenanzas de 1597 no modificaron esta situación, pero intercalaron de manera algo arbitraria el tenor del documento, con fecha de 22 de agosto de 1492, por el que el señor útil del molino de Mislata, Galceran Bou, reconoció (en acto recibido, al parecer, por Lluís Masquefa), sus deberes de mantenimiento de la acequia aguas arriba del ingenio hasta el aliviadero (almenara) conocido como de mossén Jaume Gil (nombre de un antiguo propietario del molino). El documento se produjo en el contexto de la grave crisis generada en 1491 por la rotura de cajero, aguas arriba del molino. Con él se puso fin a los conflictos derivados de la falta de precisión de la sentencia arbitral de 1434 en cuanto a la asignación de tareas de mantenimiento del sistema de Favara al titular del ingenio. Su relevancia explica que las ordenanzas de 1701, de cuidada, sintética y equilibrada redacción, presenten también inserto su texto íntegro bajo la rúbrica, "Conserve los caixers en dit districte" (CXX); uno de los dos preceptos que, por vez primera, establecían en las ordenanzas de la acequia de Favara normas expresas de aplicación al molino de Mislata (CXIX y CXX).

\subsection{La actividad de la acequia de Favara entre 1490 y 1521}

El tercer y último bloque de contenidos (ff. 31r-111r) es el más extenso y el menos coherente, desde el punto de vista de su organización (al no presentarse agrupadas las tipologías documentales diferenciadas, y no respetarse por completo la ordenación cronológica), y debido a la presencia de lagunas documentales. En él las pretensiones de belleza compositiva ceden por completo al afán de documentar los hechos y acuerdos de la acequia, a menudo con un laconismo propio de las minutas.

Masquefa habría comenzado a elaborar este grupo de cuadernos de manera plenamente consciente tras su elección como escribano de la acequia. Como hemos visto, la nota fechada el 12 de abril de 1490 que encabeza el bloque indica: "fuy fet yo Luís Masqueffa notari, escrivà de la dita céquia, e per ço en lo present llibre continue tots los actes de aquella". Llama la atención, no obstante, la falta de documentación relativa al período 1492-1503, que puede atribuirse bien al cese temporal en la escribanía de la acequia por Lluís Masquefa o bien (opción que nos parece más probable) a la pérdida de un cuaderno que debía ir entre los folios 49 y 50, que acaban y comienzan, respectivamente, con actos recibidos los días 8 de julio de 1493 y 5 de agosto de 1504. Otro periodo que presenta lagunas es el referente al formidable impacto de la revuelta de la Germanía que afectó y alteró también el normal funcionamiento de la acequia, como es obvio. Así pues 
constatamos que durante la toma del control por parte de la Germanía de los resortes de poder no se continuaron las actas, posiblemente por la huida del notario o porque la conflictividad que supuso no permitió la realización de acto alguno referente a la gestión habitual. En cualquier caso desde el 31 de mayo de 1520 hasta el 11 de noviembre de 1521 no se registran actas.

Pese a las mencionadas pérdidas de información, esta sección del volumen abre de par en par una ventana para el estudio a la dinámica interna de la acequia en el tránsito del siglo XV al XVI. La documentación es de muy diversa naturaleza, pero pueden identificarse una serie de subconjuntos documentales de especial relevancia, como serían las veintidós actas que recogen lo tratado en ajusts del Comú, de las cuales diez son actas de reuniones ordinarias convocadas al efecto de "arrendar la acequia, elegir oficiales y otras cosas necesarias" (fórmula empleada en la época) en 1490, 1492, 1506, 1508, 1510, 1512, 1514, 1516, 1518 y 1519. Las doce restantes son reuniones extraordinarias, convocadas para hacer frente a hechos inesperados, como el nombramiento de oficiales ante el deceso del titular, o disponer lo necesario ante situaciones catastróficas, como roturas del cajero. Tanto las reuniones ordinarias como las extraordinarias se celebran por lo general en la Sala del Consell de la ciudad de Valencia (uno de los espacios de poder más relevantes del reino), previa convocatoria mediante pregón público (crida) hecha por el pregonero oficial de Valencia (el trompeta públic de la ciudad) en los lugares clave de la geografía de la acequia de Favara: los "lugares acostumbrados", que, de acuerdo con el pregón efectuado el 13 de diciembre de 1517 (f. 94v), serían la ciudad de Valencia y los lugares de Patraix, Benetússer, Albal, Catarroja, Massanassa, Alfafar y Russafa.

La norma respecto a la convocatoria de reuniones ordinarias, celebradas por costumbre en Pascua de Resurrección, parece ser la realización del pregón el jueves anterior a la festividad. Únicamente se documenta un ajust ordinario en fecha diferente, el celebrado el 22 de octubre de 1508. La notoria irregularidad impulsó al escribano Masquefa a anotar una nota justificativa al margen del folio, donde leemos que la causa del gran retraso radicaba en el impacto de la mortandad habida ese año, atribuible al embate de la peste en territorio valenciano (Belenguer, 2012, p. 71): "En lo present any foren grans morts e per ço s'i detardà tant lo arrendament de la céquia" (f. 57r).

Otra anomalía reseñable es la celebración en 1519 de una reunión ordinaria del Comú, tan sólo un año después de la celebración de la última, cuando lo habitual, como se ha dicho, era el arriendo de la acequia por dos años. La causa de la anomalía, no obstante, se retrotrae a 1517. Ese año el impacto de una gran riada del Guadalaviar había causado considerables destrozos. El cequiaje de 5 diners por cahizada acordado en la subasta de 1516 resultó insuficiente para hacer frente a los gastos. Se acordaron nuevas derramas a pagar por los usuarios del sistema, pero la gravedad de la situación debió obligar a la comunidad de regantes a adoptar una solución radical: en el ajust del 5 de abril de 1518, los hereters decidieron que el Comú tenía que asumir por un año la gestión directa de la acequia, designando dos hereters para el ejercicio del oficio de sequier a cambio de un salario de 25 libras, acordando un cequiaje de 9 diners por cahizada y una derrama extraordinaria de 3 sous por cahizada para amortizar créditos. En 1519 el Comú recuperó el sistema tradicional de gestión parcialmente externalizada mediante la subasta del sequiatge.

Ante eventos inesperados que requerían soluciones expeditivas, el Comú solía responder delegando en comisiones ad hoc de hereters la búsqueda, propuesta y aplicación de soluciones, mediante acuerdo expreso adoptado en reunión ordinaria o extraordinaria. En dichas comisiones participan habitualmente otros oficiales y cargos de la acequia, junto al 
sequier y los veedors, caso del sindic (síndico), representante legal de la comunidad, habitualmente un experto en leyes con conocimientos contables, o los diputats (diputados), dignidad ejercida por las personalidades de mayor estatus que formaban parte de la comunidad de regantes: de ordinario, miembros del estamento nobiliario con señorío sobre una población (senyors de llocs).

Las funciones del sequier y, en menor medida, de los veedors, están expresamente definidas por las ordenanzas. El cometido de los otros oficiales reseñados, por el contrario, no está expresamente definido, aunque se puede deducir mediante la lectura "en negativo" de los preceptos reguladores de la actividad del acequiero. Más allá de la posibilidad que permite la documentación de completar el catálogo de oficiales y cargos de la acequia (en tiempos de Masquefa, sequier, lloctinent de sequier, veedors, guarda, partidors, sindic, diputats, escrivà, clavari y col:lector), y de perfilar sus funciones, derechos y obligaciones, en esta primera aproximación al manuscrito interesa sobre todo señalar que la capacidad de acción de las mencionadas comisiones ad hoc estaba limitada por la obligación de responder ante el Comú. Existen, sin embargo, indicios que apuntan hacia un mayor apoderamiento del rudimento de órgano colegiado, en dirección al modelo oligárquico de control de la comunidad por una Junta de Electos consagrado por las ordenanzas de 1701. Es el caso de la facultad, acordada en conjunto a diputats, sindic y veedors, de poder añadir nuevos capítulos de plena validez y obligatorio cumplimiento por el sequier, establecida por el capítulo 65 de las ordenanzas compiladas por Masquefa, ya en vigor en 1446:

LXV De poder enadir als presents capítols

Ítem, que si la céquia e/o lo Comú de aquella freturava de algun capítol ultra los dessús scrits, lo qual fos necessari e profitós a la dita céquia he Comú de aquella, que en tal cars los diputats, síndich e vehedors hordenen tal capítol, e aquell \puxen/ ajustar als presents, [e] lo cequier sia tengut tenir e observar aquell e aquells capítols a axí de nou ordenats axí bé com los presents.

Otro notable subconjunto de documentación dentro de esta sección del volumen es la integrada por los actos registrados por el escribano de la acequia con relación al ejercicio de la función jurisdiccional dentro de la comunidad. Las ordenanzas atribuyen al acequiero, en coherencia con la tradición y con los fueros y privilegios del reino, la resolución de disputas entre los usuarios del sistema, además de la imposición de penas por contravención de las normas comunes y otras circunstancias de especial gravedad. Así, vemos que el 26 de mayo de 1518, el sequier Simeó Resclosa impuso al caballero Jaume Sorell, alias Avellà, señor del molino d'en Saranyó, una considerable multa por desacato, fijada en 50 florines (originalmente 100 florines), al haberle acusado de ladrón en pleno juicio (el caballero habría espetado al acequiero "lo que vós dieu és anar a robar per los camins!"). El volumen transcribe un precioso conjunto de veintiséis sentencias de sequier, que suministran información de calidad para la reconstrucción del procedimiento seguido por la instancia jurisdiccional encargada de impartir justicia en primera instancia entre los miembros de la comunidad, y sus características.

Un primer elemento a subrayar es que el acequiero no imparte justicia en solitario, sino siempre acompañado y aconsejado por veedores de la acequia. Esta costumbre, enmarcada dentro de la labor de asesoramiento y control del desempeño del sequier encomendada a los veedores por la comunidad, constituía una tradición que había sido incorporada a las ordenanzas: 
Del cequier que sia jutge entre los hereters

LVIIII $^{\circ}$ Ítem, que qualsevol hereter de qualsevulla lley o condic[ió] que sia havent qüestió o debat sobre los feyt[s] pertany[ent]s al cequier per los fets de la céquia, sia tengut de fer juhí davant lo cequier e vehedors, e allí deter[me]nar la qüestió e debat, e si contrafarà, ni altre jutge fins que per aquells sia vist, encórrega en pena de [LX sous,] aplicadors la mitat al cequier e l’al[tra] mitat al Comú; e que de la dita pena no pux[a fer] gràcia lo cequier, sinó de sa part.

Hay que esperar, sin embargo, a las ordenanzas de 1597, para encontrar la incorporación expresa a las ordenanzas de Favara de la obligación de los veedors de participar en los juicios que se celebraban los jueves, con la precisión de que la obligación únicamente afectaba a los veedores de los brazos de la Huerta de Favara (lo que suponía la exclusión de los veedores de Els Llocs), y la novedad de ver al sindic sentado junto al sequier para impartir justicia (pp. 64-65):

De com los vehedors han de ser en plaça cada dijous

LXXXXVII Ítem, és ordenat per lo Comú de la céquia de Favara que los síndich, vehedors dels sinch brasos de la orta de València, ço és, lo del bras de Raujosa, y lo del bras de les Monges, y lo del bras de Gisbert, y lo del bras de Jesús, y lo del bras de la Gàbia, que tots estos sinch vehedors sien obligats de ser cada dijous allà hon se seurà lo cequier y lo síndich de la dita céquia, a pena de X sous per cascuna //[65r] vegada que hi faltaran; y que lo síndich los puga executar la dita pena sens remició ninguna, e la tal pena sia del Comú de la dita céquia, si no serà ab just impediment de malaltia, o per ser fora de la orta de Valencia; y açò per tantes voltes com hi faltaran.

Los veedores no solo actuaban de oficio, sino que lo hacían previo conocimiento y consentimiento de las partes, lo que pone de manifiesto el influjo del procedimiento arbitral, que impregnaba incluso el modo de proceder de los tribunales de la administración de la corona (Martínez, en prensa). Se documenta, de hecho, el concurso de árbitros expresamente designados por las partes, además de los veedores. El pleito que enfrentaba a los hereters labradores Galceran de Luna, Pere de Burgos, Joan Orts, Jaume Rolós, Jaume d'Alpont y Miquel Cucala con un tejedor de lino apellidado Mas, que pretendía construir un molino en la acequia de la que regaban los primeros, fue resuelto por sentencia pronunciada en 1513 por el sequier de Favara Jordi Soriano, los veedors Joan d'Alapont, Antoni Llorens i Pere d'Orient, junto con Antoni Despí y Bartomeu Alberola, el primero calificado de "juez o árbitro" ("judge o àrbitre") elegido por los hereters, y el segundo de "àrbitre" elegido por el tejedor Mas (f. 73r-v).

$\mathrm{Al}$ parecer, las partes tenían derecho a reclamar un nuevo juicio al sequier si consideraban que los veedores no habían actuado correctamente; juicio en el que debían participar como asesores otros veedors. Así, Bartomeu Belda (o Albelda) solicitó que el pleito "fuese revisado con otros veedores" ("fos revist ab altres veedors") al serle notificado el 26 de marzo de 1514 el fallo contrario a sus intereses emitido por el sequier de Favara, aconsejado por los veedores Pere Ceriol y Jordi Soriano (ff. 79v-80v). Conviene subrayar, asimismo, que quienes se consideraban agraviados podían recurrir a instancias jurídicas exteriores a la comunidad, habitualmente la Corte de la Gobernacion de Reino, como probó Thomas F. Glick en su clásico estudio Regadío y sociedad en la Valencia medieval, magistral análisis de las comunidades de regantes medievales valencianas, fundamentado en buena medida en las actas de los pleitos en materia de riego sustanciados ante la Gobernación (Glick, 2003 [1970]).

Otra constatación relevante es que la conexión espacio-temporal resultado del cruce de los vectores "jueves por la mañana" y "plaza de la Seo" constituía un cronotopo característico del proceder de la justicia impartida de forma autónoma por la comunidad de regantes de 
la acequia de Favara. Thomas F. Glick publicó una sentencia del sequier de Favara Bonanat Prats que fue promulgada el jueves 30 de marzo de 1419 "en la plaça de la Seu de la ciutat de València, denant la porta dels Apòstols" (Glick, 1967).

No obstante, la presencia del sequier y veedors en la plaça de la Seu no se limitaba a los jueves. Si no se encontraban ocupados por labores directamente relacionadas con el manejo de la acequia, los hereters podían encontrarlos en la plaza los días laborables, donde atendían otras cuestiones, entre ellas las relacionadas con el procedimiento judicial propio de la comunidad. Siguiendo este uso, el miércoles 26 de junio de 1493, Miquel Serra y Joan Escolano, procurador de Úrsula Andreu, requirieron al sequier Pere Jornet y los veedors Pere Ceriol y Pere Serra la asignación de día para la publicación de sentencia, puesto que ya se había practicado inspección ocular del lugar del conflicto. De acuerdo con el escribano de la acequia, el acequiero y los veedores estaban ese miércoles en la plaza de la Seu, "donde aquellos acostumbran a sentarse para dar razón de sus oficios" ("existents en la plaça de la Seu de la present ciutat, hon aquells acostumen seure per dar rahó de sos officis"). Los oficiales emplazaron a las partes a comparecer allí mismo a las 7 de la mañana del día siguiente ("feren asignació a \aquells a/ hoyr declaració per a demà a set ores en lo dit loch, ço és, a la dita plaça de la Seu"). El jueves por la mañana los tres oficiales publicaron la sentencia, en ausencia de Miquel Serra y a instancia de Joan Escolano, al haber dado ya las 8 de la mañana ("sonades huyt hores de mati").

Otro hecho a subrayar es que se documenta la promulgación de sentencias conjuntas por sequiers de dos acequias diferentes, con el concurso de veedors de ambas y de labradores expertos en materia de riego procedentes de comunidades de regantes de la ribera contraria del río. Este último rasgo constituye otro efecto del influjo del procedimiento arbitral sobre el procedimiento jurídico de las comunidades autónomas de regantes, que abre sugerentes perspectivas con relación a los orígenes de la singular actividad procesal que se desarrolla ante el Tribunal de las Aguas de la Vega de Valencia (Martínez, en prensa).

Así, el viernes 4 de septiembre de 1505, el pelaire Joan Domènec y Joan Roig, vecinos de Valencia, comparecieron ante el sequier de Favara, Jordi Soriano, i el sequier de Les Marjals, Galceran de Luna, quienes les notificaron su pronunciamiento (f. $54 \mathrm{r}-\mathrm{v}$ ). Joan Doménec pretendía regar sus posesiones haciendo parada en una acequia, y Joan Roig se oponía, alegando daños a sus tierras. Los acequieros fundaron su pronunciamiento, favorable a Roig, en la declaración verbal de testigos, la inspección del lugar de los hechos, la realización de un ensayo de riego según el modo que pretendía Doménec ("feta speriència de fer fer la parada del dit en Johan Domènech e regar los camps de aquells si's faria lo dan que lo dit en Johan Roig pretenia"), y el consejo de seis personas: los veedores Jaume Puig y Pere Ceriol, por Favara; Antoni Resclosa, vecino de Benetússer, y Joan Alapont, "vehedor de les céquies de les Margals", por la comunidad de Les Marjals; y dos labradores de poblaciones radicadas en la ribera izquierda del Guadalaviar: Andreu Pérez, de Campanar, y Bernat Palau, del camino de Alboraia.

Por último, señalar que la justicia autónoma de las acequias se fundaba en buena medida en la oralidad: pero la escritura tenía una clara presencia, como medio de prueba admisible y como herramienta capaz de aportar mayor seguridad jurídica a la comunidad y sus miembros. La colección de sentencias compiladas por Masquefa da cuenta de ello, en ocasiones de manera explícita.

Así, el 4 de septiembre de 1507, el acequiero de Favara Jordi Soriano y los veedores Pere Ceriol y Jaume Puig requirieron motu proprio, y no a petición de las partes, que el escribano 
Masquefa "pusiera por escrito" la sentencia que días atrás habían dado en el litigio que había enfrentado a Bartomeu Alberola con Pere Martí. Y lo hicieron "para tener memoria en el futuro" (f. 54v):

\begin{abstract}
"Attenent en dies passats haver feta certa declaració e sentència de la qüestió dejús scrita, de la qual declaració no fonch redigida en scrits, ara ab los presents redigim aquella per scrits en poder del scrivà de la dita céquia per haver-ne memòria en sdevenidor".
\end{abstract}

\title{
3 Conclusión
}

Masquefa inició la compilación de su singular volumen en 1490, tras ser elegido escrivà de Favara. Como sabemos, en aquel momento comenzó a copiar los cuadernos que integran el bloque final de contenidos, a los que el notario consideraba un "libro"; y en 1510, al parecer, llevó a cabo la copia del inventario y las ordenanzas de la acequia en el cuaderno que encabeza el volumen analizado.

Desconocemos si ordenó religar los diferentes cuadernos hacia el final de su ejercicio, o si lo hizo el depositario de sus protocolos; pero el hecho es que el volumen, de enorme valor para la comunidad de regantes, no pasó a ser custodiado por esta. De hecho, debió llegar por herencia a los descendientes del notario, y así acabó incorporado al magnífico archivo de fondos notariales custodiado por el benemérito Colegio del Patriarca. Hay que esperar a las ordenanzas de 1701 para encontrar la expresión reglamentaria de la conciencia de la comunidad acerca de la necesidad de crear un archivo propio de la acequia de Favara ("Es fasa argiu", cap. XIX).

Este hecho, contradictorio con el documentado afán de registrar por escrito los hechos y los actos considerados estratégicos para el buen devenir de la acequia, es expresión de la historicidad de la materia objeto de investigación. Asimismo, hemos constatado la indisoluble relación existente entre las dimensiones tangible e intangible del sistema de regadío de Favara, de manera que la intelección y valoración del registro escrito dejado por la comunidad de regantes exige el conocimiento de la geografía física de la red de acequias y su evolución.

El análisis en profundidad la acequia de Favara, como el de las restantes comunidades de regantes históricas de la Huerta de Valencia debe ser llevado a cabo, pues, con perspectiva plurisecular y sobre la base de la integración del producto del vaciado sistemático de las fuentes archivísticas relevantes con la información suministrada por el registro arqueológico extensivo e intensivo, la fotogrametría, la cartografía histórica y el registro etnográfico.

El reto es grande, pero Thomas F. Glick y el recientemente desaparecido Miquel Barceló nos han indicado claramente el camino. 


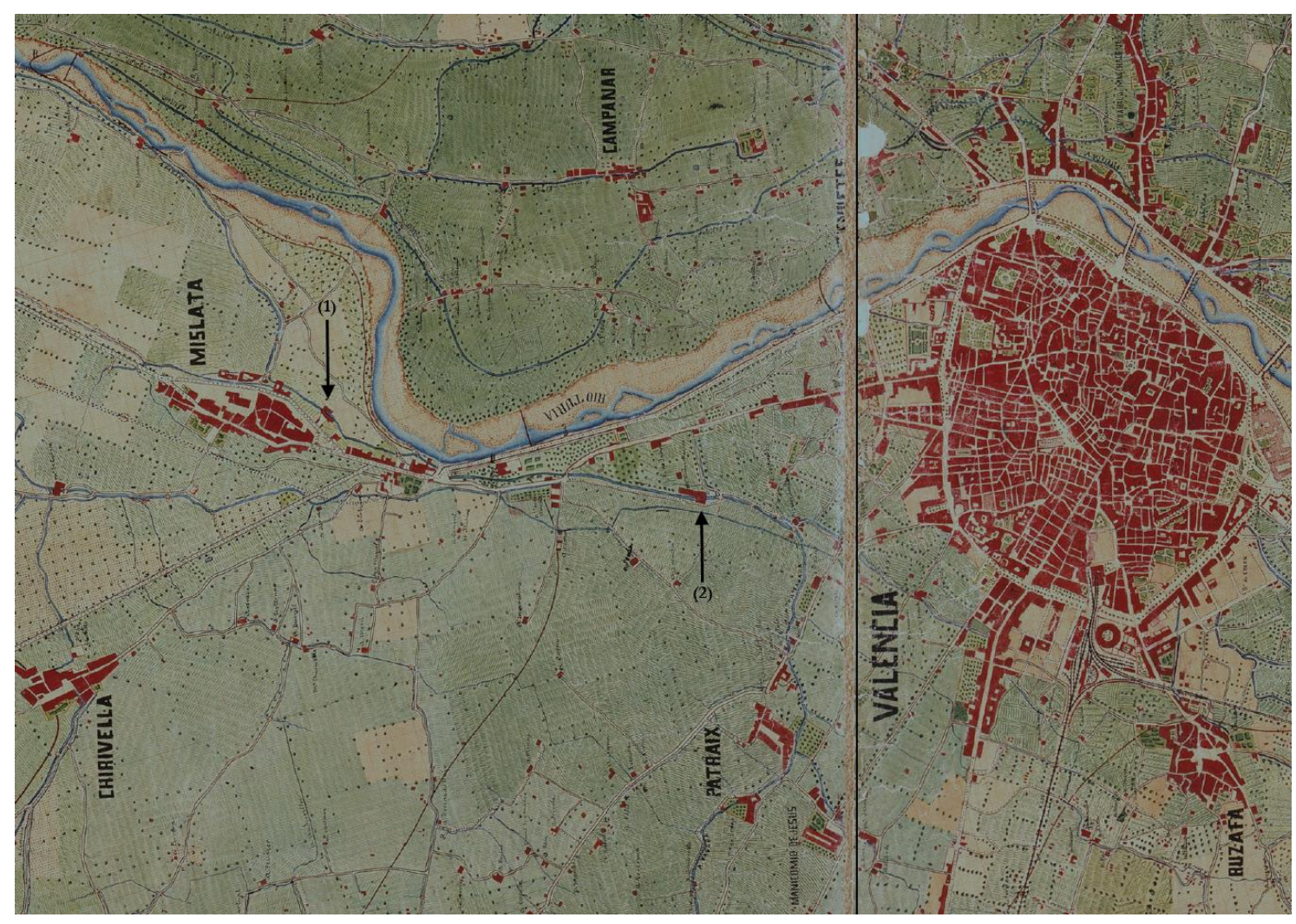

Fig. 1. Ubicación del molino de Mislata (1) y el molino de Nou Moles (2) sobre la acequia madre de Favara. Detalle del "Plano de Valencia y sus alrededores" elaborado en 1883 por el Cuerpo de Estado Mayor del Ejército. Se ha girado el plano $90^{\circ}$ a la izquierda, para que la parte superior coincida con el norte geográfico.

\section{Referencias}

Bazzana, A., y Guichard, P. (1981): Irrigation et société dans l'Espagne orientale au Moyen Age, en L'Homme et l'eau en Méditerranée et au proche Orient I. Séminaire de recherche 1979-1980, Lyon, Maison de l'Orient et e la Méditerránée Jean Poilloux, pp. 115-140.

Belenguer, E. (2012): Fernando el Católico y la ciudad de Valencia, Valencia, Publicacions de la Universitat de València.

Borrego, V., Escrivà, J. l’, y Ramírez, S. (1992): Mislata: regadiu i séquies, Mislata, Ayuntamiento de Mislata.

Glick, Th. F. (1967): Dos documentos medievales referentes al Tribunal de las Aguas, Boletin de la Sociedad Castellonese de Cultura, 43: 81-84.

Glick, Th. F. (2003 [1970]): Regadío y Sociedad en la Valencia Medieval, València, Generalitat Valenciana. 
Guinot, E. (2007a): El gobierno del agua en las huertas medievales mediterráneas: los casos de Valencia y Murcia, en G. del Ser e I. Martín, eds., Espacios de poder y formas sociales en la Edad Media: estudios dedicados a Ángel Barrios, Salamanca, Universidad de Salamanca, pp. 99-118.

Guinot, E. (2007b): Una historia de la Huerta de Valencia, en J. Hermosilla, dir., El patrimonio hidráulico del Bajo Turia: L'Horta de València, Valencia, Confederación Hidrográfica del Júcar, pp. 6098.

Guinot, E. (2012): La Huerta medieval de Valencia: origen y transformación de un paisaje histórico, dins J. Romero y M. Francés, eds., La Huerta de Valencia. Un paisaje cultural con un futuro incierto, Valencia, Publicacions de la Universitat de València, pp. 55-75.

Jaubert de Passa, F. J. (1991 [1844]) Canales de riego de Cataluña y reino de Valencia, Madrid, Ministerio de Agricultura, Pesca y Alimentación, 2 vols.

Lluch, F., y Beltrán, F. (1991): Las acequias de Francos, Marjales y Extremales de la ciudad de València, Valencia, Ayuntamiento de Valencia.

Martínez, L. P. (en prensa): Tecnoexperts, perits i sistemes hidràulics: la Séquia de Mislata i les comunitats de regants de l'Horta de València al segle XV. Recerques: història, economia, cultura.

Mateu, J., Marco, J. B., y Sanchis, C. (1999a): La huerta islámica de Valencia, en A. Furió, dir., Historia de Valencia, Valencia, Levante-EMV, pp. 50-53.

Mateu, J., Marco, J. B., y Sanchis, C. (1999b): La red de acequias, en A. Furió, dir., Historia de Valencia, Valencia, Levante-EMV, pp. 182-185.

Narbona, R. (1989): Los Rabassa, un linaje patricio de Valencia medieval, Anales de la Universidad de Alicante, $7:$ 111-136.

Rosselló, V. M. (1989): Els molins d'aigua de l'Horta de València, en Los paisajes del agua: libro jubilar dedicado al profesor Antonio López Gómez, Valencia/Alicante, Universitat de València y Universitat d'Alacant, pp. 317-346.

Sanchis, C. (2001): Regadiu i canvi ambiental a l'Albufera de València, Valencia, Publicacions de la Universitat de València, Departament de Geografia y Centre Valencià d'Estudis del Reg de la Universitat Politècnica de València.

Sanchis, C., y Ruiz, J. M. (2003): La Rambleta: aspectos geomorfológicos e hidráulicos, en V. Algarra, coord., La Rambleta de la buerta de Favara. Patrimonio bistórico y natural de la ciudad de Valencia, Valencia, Ayuntamiento de Valencia, pp. 13-30. 


\section{Rúbricas de las ordenanzas compiladas por Lluís Masquefa hasta 1519 y de las ordenanzas aprobadas en 1597 por la Gobernación del Reino de Valencia ${ }^{14}$}

\begin{tabular}{|c|c|c|}
\hline $\mathrm{N}^{\mathrm{o}}$ & Ordenanzas de Lluís Masquefa & Ordenanzas de 1597 \\
\hline 1 & De l'assut & [De l'assut] \\
\hline 2 & De[l] trenc de l'assut & De fraus de l'assut \\
\hline 3 & De metre aigua en la séquia & Al metre aigua en la séquia \\
\hline 4 & De tenir en condret [conreu] la séquia & De tenir en condret la séquia \\
\hline 5 & D'escura de la dita séquia & De l'escurar de dita séquia \\
\hline 6 & De les almenares & D'almenares \\
\hline 7 & De les ribes & De ribes \\
\hline 8 & Dels caixers de la [dita] séquia & Dels caixers de la dita séquia \\
\hline 9 & De veure les fites & De veure les fites \\
\hline 10 & De la séquia Vella & De la séquia Vella \\
\hline 11 & De l'escura, veedors i [de] tornar l'aigua & De l'escura i de tornar l'aigua \\
\hline 12 & D'herbejar & De l'herbejar \\
\hline 13 & Del sequier de Moncada & Del sequier de Moncada \\
\hline 14 & De braçals & De braçals \\
\hline 15 & Dels partidors de la Gàbia & Dels partidors de la gola \\
\hline 16 & D'haver lo sequier tanda [o tandes] & Que el sequier haja tandes \\
\hline 17 & Dels [d'aquells] qui deuen ésser sequiers & Dels que deuen ésser sequiers \\
\hline 18 & De Rovella & De Rovella \\
\hline 19 & Que estrany no siga sequier & Que estrany no siga sequier \\
\hline 20 & Dels qui venen contra la séquia & Dels que venen contra la séquia \\
\hline 21 & De plets & De plets \\
\hline 22 & De [les] despeses que deu fer lo sequier & De les despeses que deu fer lo sequier \\
\hline 23 & Del dinar e veure la séquia [escurada] & Del dinar i veure la séquia escurada \\
\hline 24 & Dels qui són francs de sequiatge & Dels que són francs de sequiatge \\
\hline 25 & Dels veedors & De veedors \\
\hline 26 & De collir les talles & De la paga del síndic \\
\hline 27 & De la paga del síndic & De collir les talles \\
\hline 28 & De[l] jurament dels lloctinents de[l] sequier & Del jurament dels lloctinents de sequiers \\
\hline 29 & De[l] jurament de sequier & Del jurament del sequier \\
\hline 30 & De les gràcies dels atandats & De les gràcies dels atandats \\
\hline 31 & Dels atandats & De les tandes \\
\hline 32 & De furtar aigua & De furtar aigua \\
\hline 33 & De [la] fermança i jurament del [dit] sequier & De la fermança i jurament del sequier \\
\hline
\end{tabular}

14 Numeración única producto de la depuración de las enumeraciones originales. Grafías modernizadas, con respeto al vocabulario específico, en ocasiones caído en desuso. La relación de rúbricas de Lluís Masquefa toma como base el índice introductorio (la "Taula dels capítols de la céquia de Favara", ff. 11v-12v) y se complementa, entre corchetes, con las variantes documentadas en la transcripción coetánea de los capítulos (ff. 13r-30v). En la relación de ordenanzas de 1597 se introducen algunos epígrafes en cursiva, entre corchetes, que corresponden a capítulos que carecen de título (rúbricas restituidas sobre la base de las ordenanzas de Masquefa). 


\begin{tabular}{|c|c|c|}
\hline 34 & Dels qui han part amb lo [dit] sequier & Dels que han part en lo sequiatge \\
\hline 35 & Que el sequier no demane ajuda & Que el sequier no demane ajuda \\
\hline 36 & Quan[t] el sequier lleixa l'assut & Quant lo sequier deixa l'assut \\
\hline 37 & De pagar les despeses & De pagar les despeses \\
\hline 38 & D'herbejar i tallar canyes & D'herbejar i tallar canyes \\
\hline 39 & D'escaixerar canyars & D'escaixerar canyes \\
\hline 40 & De cavar tarquim & Del traure tarquim \\
\hline 41 & De parades & De parades \\
\hline 42 & De guardià dels rolls & De guardià dels rolls \\
\hline 43 & D'obrir rolls & D'obrir $^{15}$ rolls \\
\hline 44 & De moliners & De molins \\
\hline 45 & De furtar aigua & De furtar aigua \\
\hline 46 & De fer parades & De fer parades \\
\hline 47 & De tancar los partidors & De tancar partidors \\
\hline 48 & De tancar aigua & De tancar aigua \\
\hline 49 & De sorregar camins & De sorregar camins \\
\hline 50 & De sorregar terra o vinya & De sorregar terra o vinya \\
\hline 51 & De bassada & De bassada \\
\hline 52 & De cavallonar & D'acavallonar \\
\hline 53 & De llevar calònies & De llevar calònies \\
\hline 54 & De denunciar penes al clavari & De denunciar les penes al clavari pel tornar l'aigua \\
\hline 55 & Dels límits del molí de Gil & Dels límits del moliner d'en Gil Pérez \\
\hline 56 & Del [de ço] que deu fer lo senyor del [dit] molí & De ço que deu fer lo senyor del dit molí \\
\hline 57 & De l'almenara del dit molí & De l'almenara del dit molí \\
\hline 58 & Del senyal de la dita almenara & Del senyal de la dita almenara \\
\hline 59 & Del sequier que siga jutge [entre els hereters] & Del sequier siga jutge entre els hereters \\
\hline 60 & De les penes del [que ha de pagar el] sequier & De penes que té de pagar el sequier \\
\hline 61 & Del sequiatge de Massanassa & Del sequiatge de Massanassa \\
\hline 62 & Que el sequiatge se deu pagar dins dos anys & Que el sequiatge es deu plegar dins dos anys \\
\hline 63 & D'escurar la séquia & De bestraure \\
\hline 64 & De bestraure & De poder anyadir als presents capítols \\
\hline 65 & De poder enadir als capítols & Del salari dels partidors \\
\hline 66 & Del salari dels partidors & Dels rolls \\
\hline 67 & Dels rolls & De pagar lo notari i escrivà de sos treballs \\
\hline 68 & De pagar el notari i escrivà [de sos treballs] ${ }^{16}$ & $\begin{array}{l}\text { De les terres que són franques els veedors del } \\
\text { sequiatge }\end{array}$ \\
\hline 69 & $\begin{array}{l}\text { De les terres que los veedors són francs de } \\
\text { sequiatge [que són franques los veedors de }\end{array}$ & $\begin{array}{l}\text { De les terres que són franques els veedors del } \\
\text { sequiatge }\end{array}$ \\
\hline
\end{tabular}

15 "De cobrir"en original.

16 Aprobada en ajust celebrado el lunes 10 de abril de 1452. Por error, el escribano computó como capítulo un párrafo introductorio, de manera que asignó a este capítulo el número 69, cuando debía ser el 68. El error de numeración se arrastra hasta el final de la relación de capítulos en el original. 


\begin{tabular}{|c|c|c|}
\hline & sequiatge $]^{17}$ & \\
\hline 70 & $\begin{array}{l}\text { Que el sequier dins el temps que escura la } \\
\text { séquia mare escure els braçals principals }{ }^{18}\end{array}$ & $\begin{array}{l}\text { QQue el sequier dins el temps que escura la séquia mare escure } \\
\text { els braçals principals] }\end{array}$ \\
\hline 71 & $\begin{array}{l}\text { Que la parada atrobada en la séquia mare prop } \\
\text { braçal de molí siga tingut dar-ne raó el moliner }{ }^{19}\end{array}$ & De parades de sobreposts de les séquies ${ }^{20}$ \\
\hline 72 & $\begin{array}{l}\text { Que degun regant de braç on hi haurà partidor } \\
\text { no puga prendre l'aigua sens [llicència del } \\
\text { partidor }]^{21}\end{array}$ & [Que el sequier no puga per infortuni deixar la séquia $]^{22}$ \\
\hline 73 & $\begin{array}{l}\text { [Que degun no puga regar alters fent parada en } \\
\text { la séquia mare sens llicència del sequier] }{ }^{23}\end{array}$ & De moliners ${ }^{24}$ \\
\hline 74 & $\begin{array}{l}\text { Que el sequier no puga per infortuni deixar [la } \\
\text { séquia }]^{25}\end{array}$ & Derrenclir la séquia el sequier ${ }^{26}$ \\
\hline 75 & & Dels que prenen aigua sense demanar-la al partidor ${ }^{27}$ \\
\hline 76 & & $\begin{array}{l}\text { Que els veedors siguen francs de sequiatge de les } \\
\text { seues terres i no de més de deu cafissades }\end{array}$ \\
\hline 77 & & $\begin{array}{l}\text { De l'escura del partidor de la Gàbia fins al partidor } \\
\text { Nou }\end{array}$ \\
\hline 78 & & Del salari de la guarda dels rolls \\
\hline 79 & & $\begin{array}{l}\text { Dels que desfan parades i llancen el fang allà on no } \\
\text { el poden llançar }\end{array}$ \\
\hline 80 & & $\begin{array}{l}\text { Dels que entren a llavar bèsties per les séquies on no } \\
\text { afronten }\end{array}$ \\
\hline 81 & & Dels que rompen caixers de la séquia de Favara \\
\hline 82 & & $\begin{array}{l}\text { Dels que rompen màrgens per llançar l'aigua de sa } \\
\text { heretat }\end{array}$ \\
\hline 83 & & Dels que furten aigua per algun braç \\
\hline 84 & & $\begin{array}{l}\text { Dels que desfan la parada de la seua regadora en } \\
\text { haver regat i llançar l'aigua }\end{array}$ \\
\hline 85 & & Dels que han de pagar el sequiatge de Favara \\
\hline
\end{tabular}

17 Aprobada en ajust celebrado el domingo 4 de abril de 1456.

18 Aprobada en ajust celebrado el 20 de mayo de 1492.

19 Aprobada en ajust celebrado el 12 de octubre de 1493.

20 Capitol aprobado el 2 de mayo de 1504, aunque en el punto de su inserción no se indique. Su contenido se repite, extractado e in extenso, otras dos veces: una de ellas, sin fecha, bajo el epígrafe "Dels que fan parades dins la céquia mare" (p. 47); la segunda, bajo el título "Dels que posen costers en la céquia mare", lleva fecha incorrecta (2 de mayo de 1509). Se mantiene la primera mención en el orden de capítulos, y se suprimen las siguientes (LXXVI, LXXVIII y LXXVIIII en original).

21 Aprobada en ajust celebrado el 28 de marzo de 1502.

22 Capitol aprobado en ajust celebrado el 6 de marzo de 1519. Por error, remite a acuerdo adoptado en ajust celebrado el 7 de marzo de 1519.

23 Aprobada en ajust celebrado el 2 de mayo de 1504.

24 Capitol aprobado el 12 de octubre de 1493. Por error, el escribano computó como capítulo un párrafo introductorio, de manera que asignó a este capítulo el número 74, cuando debía ser el 73. El error de numeración se arrastra hasta el final de la relación de capítulos en el original.

25 Capitol aprobado en ajust celebrado el 6 de marzo de 1519. Por error, el escribano del XVII indica que lo fue el 7 de marzo de 1519.

26 No se indica la fecha de su aprobación por el Comú. Su contenido se aparta de la tradición de la acequia, permitiendo que el sequier abandone sin pena alguna la administración de la acequia en caso de infortunio (contra lo aprobado, por ejemplo, el 6 de marzo de 1519.

27 Aprobada en ajust celebrado el 28 de marzo de 1502. Por error, el escribano del XVII indica que lo fue el 28 de mayo de 1502. 


\begin{tabular}{|c|c|}
\hline 86 & De com s'han de posar els costers en Favara \\
\hline 87 & De com s'ha de limitar l'aigua pels que posen costers \\
\hline 88 & Dels que fan parada al davant d'altre regant \\
\hline 89 & $\begin{array}{l}\text { Dels que no poden entrar sequier ni síndic ni } \\
\text { veedors de la séquia de Favara }\end{array}$ \\
\hline 90 & $\begin{array}{l}\text { Dels que posen aigua per braçal o regadora seca per } \\
\text { on no tenen reg }\end{array}$ \\
\hline 91 & Del com han de partir l'aigua els que posen coster \\
\hline 92 & De com els veedors han de ser a la visura \\
\hline 93 & De com els veedors han de ser en plaça cada dijous \\
\hline 94 & $\begin{array}{l}\text { Dels que han de posar coster en la séquia de Favara } \\
\text { entre els atandats }\end{array}$ \\
\hline 95 & Dels que posen coster en l'Horta de València \\
\hline 96 & Dels que prenen l'aigua pels braços que no tenen reg \\
\hline 97 & $\begin{array}{l}\text { Dels que poden mudar l'aigua d'alguna fila per altres } \\
\text { braços o rolls }\end{array}$ \\
\hline 98 & $\begin{array}{l}\text { Dels que furten aigua per regar i la guarda seguirà } \\
\text { l'aigua }\end{array}$ \\
\hline 99 & $\begin{array}{l}\text { Dels que fan parades en els partidors que no són } \\
\text { d'ells }\end{array}$ \\
\hline 100 & $\begin{array}{l}\text { Dels que obren rolls i no els tornen a tancar, i dels } \\
\text { moliners que furten aigua pels dits rolls }\end{array}$ \\
\hline 101 & $\begin{array}{l}\text { Dels que han de ser partidors de l'aigua dels braços } \\
\text { de la séquia de Favara i dels que prenen l'aigua sens } \\
\text { demanar llicència }\end{array}$ \\
\hline 102 & $\begin{array}{l}\text { Dels que desfan parades a d'aquells que reguen e el } \\
\text { tal regant seguirà l'aigua }\end{array}$ \\
\hline 103 & $\begin{array}{l}\text { De com s'han de donar les gràcies als atandats de la } \\
\text { séquia de Favara }\end{array}$ \\
\hline 104 & $\begin{array}{l}\text { De l'escura de la séquia mare de Favara que ha de fer } \\
\text { el sequier i llevar l'aigua }\end{array}$ \\
\hline 105 & $\begin{array}{l}\text { Del jurament que han de fer els que clamen i que el } \\
\text { clamater siga cregut de son jurament }\end{array}$ \\
\hline 106 & $\begin{array}{l}\text { Dels que reguen per braços de Favara que han de } \\
\text { tornar l'aigua en la séquia mare }\end{array}$ \\
\hline 107 & De que ha de fer el sequier de Favara \\
\hline 108 & De quina manera se han de posar els clams \\
\hline 109 & Del salari del síndic i escrivà \\
\hline
\end{tabular}

